\title{
EDUCAÇÃO À BEIRA DE UM ATAQUE DE NERVOS: RELATOS DE PROFESSORAS PANDÊMICAS
}

\section{EDUCATION ON THE EDGE OF A NERVOUS BREAKDOWN: REPORTS OF PANDEMIC TEACHERS}

\author{
Priscila da Cunha Bastos ${ }^{1}$ \\ Renata Rezende Gondim ${ }^{2}$
}

\begin{abstract}
Resumo: Este texto busca realizar reflexões acerca do trabalho docente nos Anos Iniciais do Ensino Fundamental durante a pandemia, ressaltando as dificuldades de atuação e as contradições impostas pelo momento de crise sanitária. A realidade vivenciada por nós, como professoras do Colégio Pedro II (CP2), é um micro recorte da situação das professoras neste período pandêmico. Apresentaremos as possibilidades desenvolvidas pelo corpo docente para manter o contato com estudantes e familiares a fim de sustentarmos os vínculos e os valores da educação escolar pública nas interações remotas, em contraposição ao que ficou disseminado como alternativa educacional para o momento: o "ensino remoto". Assim como apresentaremos algumas ações de solidariedade de classe desenvolvidas pelo conjunto de trabalhadores e trabalhadoras da instituição.
\end{abstract}

Palavras-chave: Interação remota. Educação. Pandemia. Escola pública.

Abstract: This text seeks to reflect on the teaching practice in the Early Years of elementary school during the pandemic, highlighting the difficulties of action and the contradictions imposed by the time of health crisis. The reality experienced by us, as teachers at Colégio Pedro II (CP2), is a micro-cut of the situation experienced by teachers in this pandemic period. We will present the possibilities developed by the faculty to maintain contact with students and families in order to sustain the bonds and values of public school education in remote interactions, as opposed to what has

\footnotetext{
${ }^{1}$ Professora do Departamento dos Anos Iniciais do Colégio Pedro II desde 2007 e integrante do LEDI (Laboratório de Estudos em Educação e Diversidade). Mestre (2009) em Educação e doutora em Políticas Sociais (2017) pela Universidade Federal Fluminense. Atualmente, faz parte da equipe do $5^{\circ}$ ano do campus São Cristóvão I.

${ }^{2}$ Professora do Departamento dos Anos Iniciais do Colégio Pedro II desde 2008 e integrante do LEDI (Laboratório de Estudos em Educação e Diversidade). Participou do LEDUC (Laboratório de Estudos de Leitura, Escrita e Educação) da Faculdade de Educação da UFRJ. Neste espaço, realizou o curso de extensão Alfabetização, Leitura e Escrita no ano de 2008, e o Curso de Especialização Saberes e Práticas na Educação Básica (CESPEB), no ano seguinte. Mestre pelo Programa de Pós-graduação em Educação da Faculdade de Educação da UFRJ (2016). Atualmente, faz parte da equipe do $5^{\circ}$ ano do campus São Cristóvão I.
}

Revista Lex Cult, Rio de Janeiro, v. 6, n. 1, p. 71-83, jan./abr. 2022. 
become widespread as an educational alternative for the moment: "remote education". We will also present the actions of class solidarity developed by the group of workers of the institution.

Keywords: Remote interaction. Education. Pandemic. Public school.

Recebido em: 22/10/2021 Aceito para publicação em: 08/11/2021 


\section{INTRODUÇÃO}

A vivência deste momento histórico deixa marcas em nossos corpos e, fundamentalmente, projeta uma degradação das expectativas de futuro de uma nação violentada. Os meses de isolamento nos colocaram num enfrentamento de um sobretrabalho absurdo e o prolongamento dessa situação evidencia as desigualdades de condições materiais de vida, colocando o trabalho de reprodução social, que sustenta todos os seres humanos, na centralidade.

Este texto busca realizar reflexões acerca das dificuldades de atuação docente durante a pandemia, ressaltando as contradições impostas por um modelo de "ensino" remoto. É um grande desafio, aprisionadas a práticas desgastantes, nós professoras conseguirmos produzir algum tipo de conhecimento sobre este momento. Intencionamos que, pelo menos, fique o registro do drama experienciado por nós, mulheres, mães, professoras, no trabalho remoto.

Consideramos importante expressar o lugar de onde falamos sobre este assunto. Somos professoras de uma escola pública federal, possuímos plano de carreira, salário base, gratificação por reconhecimento de saberes e competências. Somos mulheres brancas, formadas nos cursos de pedagogia de universidades federais. A estrutura organizativa da instituição na qual atuamos prevê espaços de discussões e decisões coletivas, ainda que tenhamos que lutar pela legitimidade desses fóruns. Participamos do sindicato de servidores do colégio, atuamos no quinto ano do Ensino Fundamental, com crianças entre 9 e 11 anos. A realidade vivenciada por nós, como docentes do Anos Iniciais do Ensino Fundamental do Colégio Pedro II (CP2), é um micro recorte da situação das professoras neste período pandêmico.

Tentaremos resgatar o percurso do CP2 durante o fechamento das escolas no período pandêmico no estado do Rio de Janeiro. Alguns elementos que dão sentido à nossa análise dizem respeito às portarias emitidas por essa instituição, neste período, que estabelecem o controle do trabalho docente e alteram o sentido, concepções e objetivos da ação pedagógica, promovendo "adaptações" do ensino 
presencial à lógica de "ensino" à distância.

Apresentaremos as possibilidades desenvolvidas pelo conjunto de trabalhadoras da escola para manter o contato com estudantes e familiares a fim de sustentarmos os vínculos e os valores da educação escolar pública e a luta pela organização de uma estrutura laboral que considere o sobretrabalho das mulheres e o enfrentamento do machismo institucional - pelo qual nós, professoras dos anos iniciais, somos constrangidas a provar o que estamos fazendo, como estamos fazendo e o tempo em que fazemos.

Quando, em maio de 2020 , as escolas brasileiras foram fechadas pelo risco de contaminação do coronavírus, não demorou duas semanas para que propostas rápidas fossem entregues à população. Mal sabíamos o tempo em que permaneceríamos com as escolas fechadas. Isso, inclusive, parecia ser o menos importante, já que a pandemia abria uma "janela de oportunidades" para testar um modelo de educação sem regulamentação, sem debate público, sem escrúpulos e sem a menor base pedagógica.

Ressaltamos que antes da pandemia o cenário já era devastador para nós professoras de escola pública. A precarização do trabalho docente já estava em curso, seja pela terceirização, pela falta de um plano de carreira para grande parte dos profissionais da educação, pela não regulamentação do piso salarial ou pela expansão do mercado educacional. Neste contexto, cada professora, muitas vezes, precisa trabalhar em duas ou mais escolas para complementar a renda, ainda sem horário de planejamento. Vivenciamos, em meio a pandemia, um processo de aceleração do desemprego na carreira docente também pela corrida da substituição das aulas presenciais pelas plataformas digitais (SHIROMA; EVANGELISTA, 2015; SILVA; MOTTA, 2019; COLEMARX, 2020).

A grande marca do enfrentamento da pandemia pelo Estado foi tratar problemas sociais como casos individuais, roubando as possibilidades de garantia da existência das pessoas com uma opressão sistemática e um projeto político de naturalização e funcionalização das desigualdades. É nesse cenário que o "ensino remoto" ganhou corpo, extraindo o sujeito educador e o educando de seu contexto 
social, de sua realidade material concreta, impondo uma perspectiva de culpabilização e de individualização das responsabilidades pelo processo educativo e por seus resultados. Cabe ao educando se esforçar para ter os meios adequados para acessar a aula remota, seja síncrona ou assíncrona, assim como cabe a educadora garantir os recursos necessários para filmar, editar, produzir, adaptar materiais, postar e alimentar as plataformas digitais.

No CP2, tivemos as aulas suspensas na segunda quinzena de março de 2020. Em menos de uma semana já foi apresentada a mágica solução do "ensino remoto", difundida pelos grandes meios de comunicação, colocado em prática nas escolas particulares e também, de uma maneira muito mais precária, em escolas públicas. Alguns contratos das plataformas digitais dominantes do mercado com algumas prefeituras já eram do ano anterior (2019), evidenciando que o "ensino remoto" já era um projeto, mas encontrou na pandemia a desculpa perfeita para sua implementação. Organizadas coletivamente, questionamos o tempo todo essa proposição e a naturalização do que ficou conhecido como "ensino remoto" pela exclusão digital, pelas condições diferenciadas de isolamento, pelas dificuldades de acesso, pelo fato de não poder ser considerado ensino. Já anunciávamos que era uma farsa chamar de ensino o que começamos a chamar de interações remotas, especialmente por ser uma estrutura que não necessariamente atinge os objetivos de toda e qualquer prática educativa formal: a aprendizagem significativa.

\section{2 “ENSINO REMOTO”: SURTO E VIOLÊNCIA}

Nós que defendemos a educação como um direito regido pelo princípio da igualdade de oportunidades somos atravessadas por uma perspectiva político-pedagógica que considera fundamental para o trabalho educativo o compromisso com a liberdade e a justiça para todas e todos. Como aceitar algo que é estruturado para coibir estes princípios? Como assumir como nossa uma prática educativa desenvolvida a partir de uma tela que só é acessível a poucos?

O conhecimento escolar, aquele que se dá no espaço formal da instituição 
educativa, é pensado, estruturado e organizado de maneira a atender a determinados fins. Os objetivos educacionais, aqueles que informam nossa intencionalidade na prática educativa, partem de uma não neutralidade, uma vez que o tempo inteiro nós educadoras estamos nos perguntando: o que ensinar, como, por que, para quê, para quem e quando ensinar?

Mascarar a existência de uma intencionalidade no ato de ensinar só serve para falsear os reais objetivos daquilo que a partir da pandemia do coronavírus começamos a escutar como sendo a solução de todos os males educacionais: o "ensino remoto". bell hooks (2017, p. 49) nos lembra que "[...] a cultura da dominação necessariamente promove os vícios da mentira e da negação" e o "ensino remoto", assim como o tratamento precoce, foi a grande mentira desse período.

Fruto de escolha racionais e com objetivos não declarados, esse modelo de "ensino" se mostra altamente excludente e desonesto, aprofundando as desigualdades, rebaixando e precarizando a educação com o empobrecimento do processo de ensino-aprendizagem, a transformação da educação num processo individual.

Fomos bombardeadas por um conjunto de ações desumanizantes, travestidas de ações pedagógicas. Reconhecidamente 0 adoecimento das profissionais de educação era sistêmico e agora vem se tornando estrutural. Em nossa realidade escolar, avolumam-se o número de licenças saúde. Mulheres afastadas para cuidar de si e de outros, distantes de si, de suas práticas e de sua realidade profissional.

Neste contexto pandêmico, impuseram-nos um modelo de trabalho e um modelo de educação que não só fere, mas nega o princípio constitucional da educação como um direito de todas e todos. Seria um surto coletivo? Como sustentar a defesa de um modelo que ignora o fundamento de uma educação pública e gratuita?

Do surto coletivo de defender o indefensável como alternativa, rapidamente situações de violência foram instauradas por desconsiderar as condições materiais 
de existência de alunos, alunas e professores. Fomos sendo submetidas cada vez mais rápido a uma precarização do nosso trabalho, sendo assediadas para dar conta de um modelo educativo que sabemos ser excludente.

Estamos usando nossos celulares para produzir e enviar materiais em meios digitais. Gravamos e editamos vídeos, produzimos jogos on-line, utilizamos novas ferramentas tecnológicas, fazemos cursos e nos endividamos para ter em casa os recursos técnicos fundamentais para, minimamente, garantir as interações remotas.

Além das funções docentes, estamos em casa, com nossos filhos, responsáveis pelos cuidados da casa, das crianças, dos doentes. Com nossas redes de acolhimento interrompidas pelas medidas sanitárias, implementadas para a contenção da pandemia. A normalização dessa opressão em nossos corpos, nos violenta, nos adoece.

O que pretendemos aqui é reafirmar nossa honestidade pedagógica. $O$ chamado "ensino remoto" serve para validar ano letivo, na lógica da certificação, mas não serve para dizer que cumprimos nossos objetivos educacionais. Que aprendizagens garantimos? Não há ensino basicamente porque não temos as garantias das condições estruturais que conduzam ao aprendizado escolar. Nossa honestidade pedagógica nos faz afirmar que é um surto chamar de ensino as atividades remotas. É a expressão de uma falsa solução disseminada subitamente a fim de atender a uma agenda empresarial.

Em "Pedagogia da Autonomia", Paulo Freire (1996) enfatiza nossa tarefa como educadora de perseguir a aproximação entre teoria e prática, de diminuir a distância entre o que se pensa, nossos fundamentos teórico-filosóficos e nossas ações, nossa atuação pedagógica. É isso que estamos chamando de honestidade pedagógica.

O "ensino remoto" é o coronavírus da educação, pois provoca a morte do ensino, sufoca e asfixia sonhos, atribui um caráter "[...] desesperançoso, fatalista, antiutópico em que se forja uma educação friamente tecnicista e se requer um educador exímio na tarefa de acomodação ao mundo e não de sua transformação." (FREIRE, 1996, p.143). É contra isso que resistimos e por isso somos 
constantemente atacadas. Temos a certeza de que não estamos sendo combatidas porque somos anacrônicas, mas porque podemos "anunciar o novo, podem(os) formar crianças, jovens e adultos, nos campos e cidades, que questionem a ordem social presente, que pensem historicamente e que arquitetem o futuro e a transição para outra ordem social". (SHIROMA; EVANGELISTA, 2015, p. 334).

Nossa recusa em assumir uma educação que falseia os objetivos para o qual ela é traçada, no processo de disputa dentro da nossa instituição, resultou no que foi chamado de "atividades de apoio cognitivo e emocional". Num primeiro momento, sem contagem de carga horária, elaboramos materiais interdisciplinares para que as crianças e as famílias tivessem relação com a escola e com o conhecimento que nela produzimos. No ano de 2021, com o prolongamento da pandemia, a instituição foi impelida a portariar a forma como desenvolvemos as interações remotas, com contagem de carga horária de aula, grade de horários e avaliações. Ainda assim, seguimos na contramão da naturalização deste modelo remoto. Conseguimos aprovar, por exemplo, a não reprovação de estudantes e a não realização de atividades avaliativas formais, como provas nos Anos Iniciais.

\section{ESCOLA NA PANDEMIA: NÃO É EMPATIA, É SOLIDARIEDADE DE CLASSE}

Nossa escolha coletiva no momento em que as escolas foram fechadas foi nos organizarmos para viabilizar ações de solidariedade e acolhimento às famílias. Esperávamos que a escola pudesse ser um centro de referência de informações sobre o vírus, sobre como se proteger, sobre as condições sanitárias que garantisse a saúde de todos. Afirmamos a necessidade de condições materiais para o isolamento social, assim como as condições materiais para o exercício do trabalho remoto, considerando as especificidades e ressaltando o trabalho coletivo que estávamos desenvolvendo.

Construímos, em nossos locais de trabalho, comitês de emergência a fim de mapear as necessidades das famílias e colher informações que contribuíssem para o desenvolvimento de ações políticas e pedagógicas, pois a instituição não possuía, 
até aquele momento, dados sobre a situação de acesso, saúde e emprego das famílias. Afinal,

\begin{abstract}
a compreensão dos limites da prática educativa demanda indiscutivelmente a claridade política dos educadores com relação ao seu projeto. Demanda que o educador assuma a politicidade de sua prática. (...) Não posso pensar-me progressista se entendo o espaço da escola como algo meio neutro, com pouco ou quase nada a ver com a luta de classes, em que os alunos são vistos apenas como aprendizes de certos objetos de conhecimento aos quais empresto um poder mágico. Não posso reconhecer os limites da prática educativo-política em que me envolvo se não sei, se não estou claro em face de a favor de quem pratico. (FREIRE, 2003, p. 46-47).
\end{abstract}

Assim, um Comitê de Urgência foi formado no campus em que estamos lotadas, a partir da adesão voluntária de professores e técnicos, além de duas responsáveis representantes por cada turno e uma outra responsável representante. Ele foi criado com o objetivo geral de voltar-se para as demandas emergenciais da comunidade escolar, desdobrando-se em ações como: o compartilhamento de informações oficiais no âmbito da instituição e o estreitamento do contato com as famílias dos estudantes, assim como entre os servidores.

A primeira ação do comitê foi a elaboração e envio, por e-mail, de um formulário que consistiu em importante instrumento de coleta de dados para realizar, em linhas gerais, uma sondagem acerca das condições de saúde das famílias do campus, situação de emprego/trabalho dos adultos e possibilidades de acesso à internet.

Cerca de $70 \%$ das famílias atendidas pelo nosso campus responderam ao questionário. Conseguimos uma amostra significativa da participação de todos os anos de escolaridade. Como retorno, tivemos conhecimento da dificuldade encontrada por muitas famílias em acessar as informações da escola pelo site e que muitos responsáveis preferiam receber as comunicações da escola pelo grupo da turma no celular, por exemplo. Questões como essas foram compartilhadas com todos os servidores do campus em reuniões coletivas para que repensássemos as formas de contato com as famílias. Também nos organizamos no comitê para entrar em contato com os demais responsáveis que não haviam respondido ao Revista Lex Cult, Rio de Janeiro, v. 6, n. 1, p. 71-83, jan./abr. 2022. 
questionário. Nas ligações, que foram feitas a partir de nossos dispositivos móveis, encontramos famílias em situações de moradia e condições de estudo precárias, satisfeitas em receber o contato da escola e serem de alguma maneira acompanhadas.

Como resultado das análises do questionário, verificamos que entre aqueles que permaneceram empregados, uma boa parte teve redução salarial. Encontramos situações em que pelo menos um membro da família estava desempregado. A maioria se encontrava em boa situação de saúde, mesmo os que eram considerados do grupo de risco.

No que se refere aos aspectos pedagógicos, especificamente ao acompanhamento e realização das atividades postadas no blog do campus, as famílias respondentes relataram que quando acessavam o conteúdo notavam desinteresse das crianças nas atividades e/ou falta de tempo para organizar a realização das mesmas. É preciso considerar que essas atividades não tinham um caráter conteudista e apostavam num acolhimento cognitivo e emocional, visando a manutenção do vínculo com a escola.

Identificamos que, como forma de manter a continuidade dos estudos em casa, algumas famílias contrataram explicadora, uma professora particular para dar aula aos filhos. Fomos questionadas sobre as escolhas pedagógicas feitas pela instituição, mas, ao mesmo tempo, as famílias relatavam concordância com a posição da escola sobre a não adesão a um modelo de "ensino" remoto, que previa a participação on-line das crianças e do acesso a plataformas de ensino.

A partir dos comitês e de estratégias realizadas pelos campi, se evidenciou para a instituição que grande parte das famílias não possuía dispositivos e nem plano de acesso à internet. Ao longo da pandemia, foram implementadas algumas políticas que previam auxílio financeiro para que as famílias obtivessem dispositivos e planos de internet.

Paralelamente ao início dessa pesquisa, o comitê iniciou sua campanha de solidariedade às famílias necessitadas do campus e se engajou na campanha de arrecadação de doações em dinheiro, promovida pelo Sindicato dos Servidores do 
Colégio Pedro II - SINDSCOPE - para prover auxílio a um grupo de trabalhadores terceirizados da limpeza que teve seus contratos finalizados.

A experiência do comitê de emergência constituído no campus onde atuamos contribuiu para o desenvolvimento tanto de ações de solidariedade com as famílias como para dar corpo ao debate institucional da necessidade de auxílio aos estudantes e a não sujeição a um modelo de educação altamente excludente.

De acordo com o Relatório de Gestão do ano de 2020 do CP2, foram oferecidos os seguintes auxílios aos estudantes devido à pandemia: auxílio estudantil emergencial para 3611 estudantes, em três parcelas de quatrocentos reais; auxílio estudantil financeiro inclusão digital a 2701 estudantes para compra de dispositivo e plano de internet, no valor de oitocentos e sessenta reais.

Disputamos internamente e externamente o debate acerca das funções e objetivos da escola pública durante a pandemia. Tentamos, de alguma maneira, manter o vínculo dos estudantes e das famílias com a escola, reforçando o valor da educação pública para a formação dos filhos e filhas da classe trabalhadora. Durante o ano de 2020, desenvolvemos projetos pedagógicos que consideravam as condições materiais de vida de estudantes, relacionando conhecimentos de diferentes áreas ao momento vivido, sem cobrança de faltas, sem cobrança de notas, sem reprovações. O que precisa ser dito é que nós não nos propusemos a falsear as relações de ensino-aprendizagem como se bastasse adaptar o modelo presencial ao remoto. Nós construímos formas de contato com a escola e com o conhecimento não submetidas às estruturas formais do processo educativo. Teremos que construir agora, coletivamente, as alternativas para amenizar os impactos pedagógicos desse período, formulando políticas a longo prazo e, sobretudo, repensando práticas e currículos que se comprometam com este objetivo.

\section{CONSIDERAÇÕES FINAIS: O ATAQUE DE NERVOS}

Não há, como já afirmamos, neste modelo remoto, especialmente com 
crianças, como garantir aprendizagens nos termos que defendemos, aquelas aprendizagens significativas para o sujeito estar no mundo, pensando sobre o mundo e criando possibilidades de nele intervir. Isso não significa dizer que aprendizagens não foram realizadas, até porque somos sujeitos de aprendizagem, em qualquer relação que desenvolvemos. O que queremos afirmar é que as intencionalidades educativas formuladas pelos currículos escolares, no modelo remoto, não são passíveis de aferição. Aqueles que dizem que o fazem, mentem.

Pensar na escola pública que queremos é pensar no tipo de sociedade que queremos construir. Nós desejamos construir um mundo em que as pessoas sejam livres, tenham direitos e possam viver bem com igualdade e justiça. Não é apenas o "ensino remoto", o centro da disputa é sobre o sentido do Estado e da escola pública para a população. Precisamos afirmar o papel de grande importância da escola que, na maior parte das vezes, é a porta de acesso a direitos fundamentais e isso diz muito sobre a falta de políticas públicas, a ausência do Estado. Ela em si não soluciona todos os problemas sociais. Na verdade, a escola, ou a falta dela, ressaltou durante a pandemia a inexistência de políticas complementares - como política de renda para as mulheres. A forma como a questão educacional foi colocada em debate público fez parecer que se as escolas fossem logo reabertas, até a pandemia estaria resolvida. Isso nos leva ao ataque de nervos!

A escola é um território que opera com contradições. Por isso, é um espaço de luta constante. Nós reivindicamos o sentido da escola pública como um espaço democrático, plural, laico, de qualidade comprometida com o combate às desigualdades e potencializadora dos sujeitos. Uma escola que, como Paulo Freire (1996) disse, tem também a "tarefa político-pedagógica de desocultar verdades". Esse é o sentido da escola que nos interessa. Nossos estudantes estão em interação remota há quase dois anos porque as alternativas elaboradas de combate à pandemia não foram eficientes. Enfrentam dificuldades de acesso, necessidades de mediação, dificuldades de aprendizagem on-line, anseiam pelo retorno seguro, assim como nós. Será preciso um compromisso global coletivo para que toda a sociedade construa os caminhos possíveis para amenizar o impacto desta vivência 
da pandemia nas nossas vidas e nos processos de escolarização dos estudantes.

\section{REFERÊNCIAS}

COLÉGIO PEDRO II. Relatório de Gestão - 2020. [s.I.]: MEC, 2021. Disponível em: http://www.cp2.g12.br/images/comunicacao/2021/MAIO/RG\%202020\%20Completo \%20final.pdf. Acesso em: 22 nov. 2021.

COLEMARX. Em defesa da educação pública comprometida com a igualdade social: porque os trabalhadores não devem aceitar aulas remotas. Rio de Janeiro: Colemarx/UFRJ, 22 abr. 2020. Disponível em:

https://colemarx.educacao.ufrj.br/wp-content/uploads/2020/09/Colemarx-texto-cri\%C C\%81tico-EaD-2.pdf. Acesso em: 22 nov. 2021.

FREIRE, Paulo. Pedagogia da Autonomia. São Paulo: Paz e Terra, 1996.

FREIRE, Paulo. Política e Educação. São Paulo: Cortez, 2003.

HOOKS, bell. Ensinando a transgredir: a educação como prática da liberdade. São Paulo: Editora WMF Martins Fontes, 2017.

SHIROMA, Eneida Oto; EVANGELISTA, Olinda. Formação humana ou produção de resultados? trabalho docente na encruzilhada. Revista Contemporânea de Educação, Rio de Janeiro, v. 10, n. 20, p. 314-341, jul./dez. 2015. Disponível em: https://revistas.ufrj.br/index.php/rce/article/view/2730. Acesso em: 22 nov. 2021.

SILVA, Amanda Moreira da; MOTTA, Vânia Cardoso da. O precariado professoral e as tendências de precarização que atingem os docentes do setor público. Roteiro, Joaçaba, v. 44, n. 3, p. 1-20, set./dez. 2019. Disponível em: https://portalperiodicos.unoesc.edu.br/roteiro. Acesso em: 22 nov. 2021. 